\title{
Pleural space oddity: The relevance of Boyle's and Laplace's laws in the skies
}

\author{
Stephen D. Cassivi, MD, MSc, FRCSC, FACS
}

\author{
From the Division of General Thoracic Surgery, Department of Surgery, Mayo Clinic, Rochester, Minn. \\ Disclosures: Author has nothing to disclose with regard to commercial support. \\ Received for publication March 2, 2016; accepted for publication March 4, 2016; available ahead of print April 5 , \\ 2016. \\ Address for reprints: Stephen D. Cassivi, MD, MSc, FRCSC, FACS, Division of General Thoracic Surgery, Mayo \\ Clinic, 200 First St SW, Rochester, MN 55905 (E-mail: cassivi.stephen@mayo.edu). \\ J Thorac Cardiovasc Surg 2016;152:e3-4 \\ $0022-5223 / \$ 36.00$ \\ Copyright (C) 2016 by The American Association for Thoracic Surgery \\ http://dx.doi.org/10.1016/j.jtcvs.2016.03.013
}

In the interesting case report and discussion presented by Khawar and colleagues in this issue of the Journal, the salient issues of intrathoracic cysts, lung disease, air travel, and pleural physiology are brought together for consideration. ${ }^{1}$ This provides us with the opportunity for a thoughtful review of these matters as they pertain not only to this case, but also more generally to patients who we have the privilege to treat every day.

Cysts in the chest and mediastinum are collectively a large assortment of conditions that are relatively rare as individual entities. They can present in a variety of ways or may often be asymptomatic, only found incidentally or when a complication occurs, as in the case under review. These cysts are occasionally a diagnostic challenge, and their treatment is usually predicated on their underlying diagnosis, anatomic location, and related symptoms. ${ }^{2}$ In the case reviewed, the large cyst is lined with what appears to be ciliated epithelium as would be found in a bronchogenic cyst. Where this case differs from the usual is in the finding of an air-filled cyst with apparent communication to the bronchial tree. Typically, bronchogenic cysts do not communicate with the airways and are usually filled with amorphous acellular material. The authors' description of an air-filled cyst within the posterior segment of the left upper lobe with connections to the pulmonary vein increases the likelihood that this was an atypical example of a unilocular congenital pulmonary airway malformation type 1 (CPAM1). ${ }^{3}$ This becomes significant in that atmospheric pressure changes, especially in respect to the pleural space, are important only in the consideration of self-contained air-filled cysts or collections. Air pressure changes are, for all practical purposes, irrelevant for fluid filled cysts, as is the usual case for uncomplicated bronchogenic cysts.

This leads to consideration of the phenomena occurring in the pleural space when it is subjected to the hypobaric conditions of an airplane flight. The authors appropriately make reference to Boyle's law, which is indeed in play. Simply put, Boyle's law states that at a

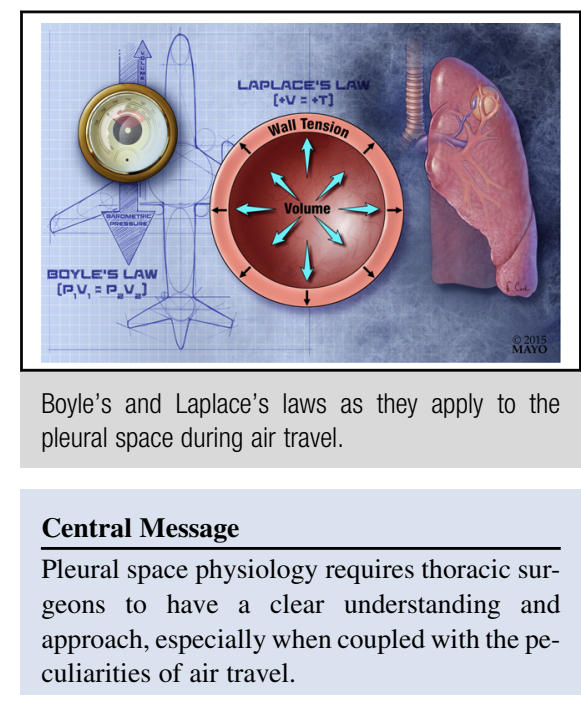

See Article page e1.

constant temperature, a decrease in the pressure of a gas will be accompanied by an increase in volume of the gas. This is why even the diminutive bag of pretzels, having started with an insignificant amount of air within it at ground level, seems to have inflated to almost bursting when handed out midflight. This phenomenon also occurs with any similarly trapped air collection, such as an air-filled cyst or pneumothorax.

The authors' assertion that with increased volume there is resultant increased "pressure" is incorrect, however. Indeed, this cannot be the case, because here the pressure is a function of the hypobaric milieu of the airplane cabin. It is the decrease in pressure experienced with the increased altitude during air travel that leads to an increase in the volume of any trapped gases. The authors seem to want to depict the different but equally relevant phenomenon of wall tension described by Laplace's law, which states that as volume increases within a container, so too does the wall tension of the container (Figure 1). This fits with the authors' case, in that the hypobaric environment of the airplane cabin causes the volume of gas in the air-filled cyst to increase. As the cyst volume increases, so too does its wall tension, possibly resulting in injury to the wall and any microvasculature within the wall. This seems to be the hypothetical explanation for the etiology of air entering the vascular system with the resultant air embolism.

Although this case illustrates a severe outcome experienced during air travel, this particular case clearly 


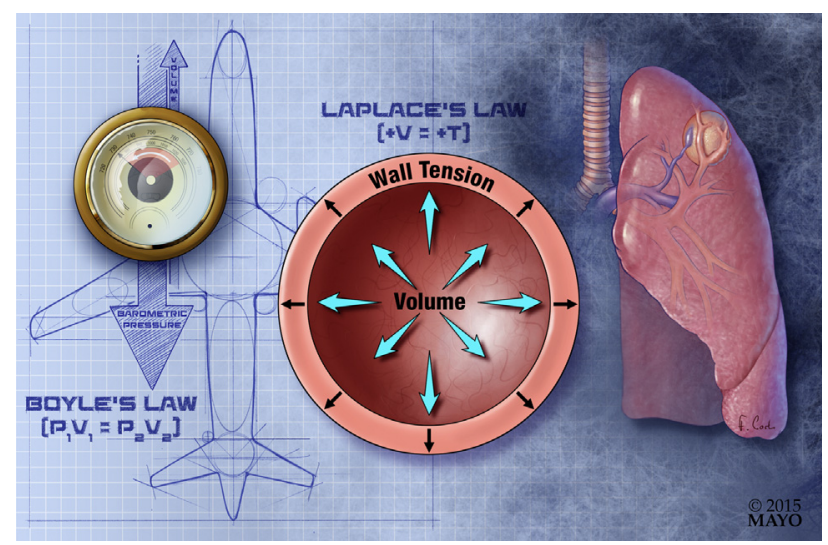

FIGURE 1. Boyle's and Laplace's laws as they apply to the pleural space during air travel.

remains an extremely rare event. What is not rare is the increasing number of patients traveling by air to obtain medical care, including thoracic surgical interventions. In our practice at Mayo Clinic, $10 \%$ to $15 \%$ of patients undergoing a pulmonary resection return home by air travel. Unfortunately, current safety guidelines regarding air travel after lung surgery remain limited to ad hoc recommendations from individual commercial airlines and the more formal and very conservative Aerospace Medical Association guidelines published more than a decade ago and based solely on "expert opinion" given the lack of published research in this field. ${ }^{4}$
In a retrospective review of our experience comparing patients returning home by ground or air after a pulmonary resection, we found no difference in the rate of complications in the 30 days after hospital dismissal. ${ }^{5}$ These findings support our current practice of allowing patients to return home by air travel after pulmonary resection using the same criteria of general clinical stability used for patients traveling by ground transportation. Specifically, the 3 main factors used to determine whether a patient is suitable for dismissal from hospital after pulmonary resection remain applicable for patients returning home by ground or by air are the absence of an ongoing air leak, postoperative pain under adequate control, and suitable oxygen saturation with exercise.

\section{References}

1. Khawar M, Elmahrouk A, Chaikhouni A. Air embolism during air flight in a passenger with bronchogenic cyst. J Thorac Cardiovasc Surg. 2016;152: e1-2.

2. Makhija Z, Moir CR, Allen MS, Cassivi SD, Deschamps C, Nichols FC, et al. Surgical management of congenital cystic lung malformations in older patients. Ann Thorac Surg. 2011;91:1568-73.

3. Stocker JT. Cystic lung disease in infants and children. Fetal Pediatr Pathol. 2009; 28:155-84.

4. Aerospace Medical Association Medical Guidelines Task Force. Medical guidelines for air travel (2nd edition). Aviat Space Environ Med. 2003; 74:A1-19.

5. Cassivi SD, Pierson KE, Lechtenberg BJ, Wigle DA, Nichols FC, Shen KR, et al. Safety of air travel in the immediate postoperative period following anatomic pulmonary resection. J Thorac Cardiovasc Surg. 2016 [In review]. 